\title{
Dynamic Voltage Restorer (DVR) Improve Operation of DFIG Wind Turbine Under Unbalance Grid Voltage Sags
}

\author{
Xiaojie Wang ${ }^{1, a}$, Junqing Chen ${ }^{2, b}$, Fan Yang ${ }^{3, c}$, Yongfeng Ren ${ }^{3, d, ~ *}$ \\ ${ }^{1}$ Xilingol Vocational College, Xilinhot, 026000,China \\ ${ }^{2}$ Beijing Jingneng New Energy Co. Ltd. Huitengxile wind branch, Ulanqab, 013550,China \\ ${ }^{3}$ Inner Mongolia University of Technology, Huhhot, 010051,China \\ a593951164@qq.com, bjq.321@163.com, cyang93617@qq.com, 'renyongfeng@vip.sina.com, \\ "corresponding author
}

Keywords: Dynamic Voltage Restorer(DVR), Doubly Fed Induction Generator(DFIG), Grid Voltage Sags, Operation, Resonance Integrator(RI)

\begin{abstract}
In view of the doubly-fed wind power generator (DFIG) under grid voltage unbalance, double frequency disturbance component will cause a series of electrical and mechanical problems. A novel DFIG-DVR system is proposed to ride-through unbalance grid voltage conditions, the series coupled DVR of which always maintain the constant of stator voltage, isolating primary causes of problems for grid voltage unbalanced fault. In the process of fault operation, DFIG can still achieve the target for rotor side converter to accomplish decoupled power control and grid side converter to maintain constant on dc voltage. DFIG-DVR system model was established by MATLAB/Simulink. Comparison and analysis are conducted about whether DVR is switched under the condition of unbalanced grid voltage. The simulation results show that the proposed control scheme can realize low voltage ride-through(LVRT) operation of DFIG under the conditions of unbalanced grid voltage.
\end{abstract}

\section{Introduction}

Nowadays, doubly fed induction generator(DFIG) have been increasing greatly, which makes people don't ignore its stability and security impacts caused by the grid voltage fault[1] [2]. A detailed and clear review of gird codes is prescribed in [3], considering the fault ride-through behavior as well as steady-state active power production and adequate reactive to support and restore quickly the grid voltage after the grid fault. For stable operations during grid voltage faults, the grid code also requires wind turbines to withstand transient degree of unbalance up to $4 \%$ or higher, and withstand steady state of $2 \%$ without split.

Since the stator of DFIG is directly connected to the grid, the DFIG is more sensitive to grid disturbances. Once in unbalanced grid voltage conditions, it is a negative sequence produced to the stator flux that larger negative-sequence currents flow through the stator and rotor, which results in additional harmonic double-frequency fluctuations in the power and electromagnetic torque. Hence, to meet new grid code, it is necessary that the wind turbines have the capability to operate smoothly by valid control strategy or auxiliary hardware under unbalanced grid voltage conditions.

Conventionally, there are many approaches to use novel control schemes to limit the impact of unbalance. Multiple control targets are a popular method by setting of the references, from which coordinating the control of the RSC and the GSC[5] and predictive current control [6] are investigated. In [8], using two resonant controllers and a PI controller, the improved direct power control (DPC) strategy can maintain constant stator power, eliminate torque pulsations and maintain sinusoidal stator current.

In this paper, the application of a DVR to enhance the stable operation capability is investigated in which the DVR is connected in series between the grid and the wind turbine generator. The stator voltage can be kept constant by injected DVR output voltage, by which the grid disturbances have no effect on the generation operation. In addition, separation method of the positive and negative 
sequence and detailed compensation principle are given. The validity of the proposed DFIG-DVR with three single phase structure is shown by simulation results.

\section{Dynamic Model of DFIG}

The topology of DFIG system with DVR as shown in Figure1. The stator of DFIG adopts generator convention and positive direction of electromagnetic torque is contrary to the direction of rotation. Meanwhile, the rotor of DFIG adopts motor convention. The dynamic equivalent circuit of generator in synchronous rotating reference frame is shown inFigure2.

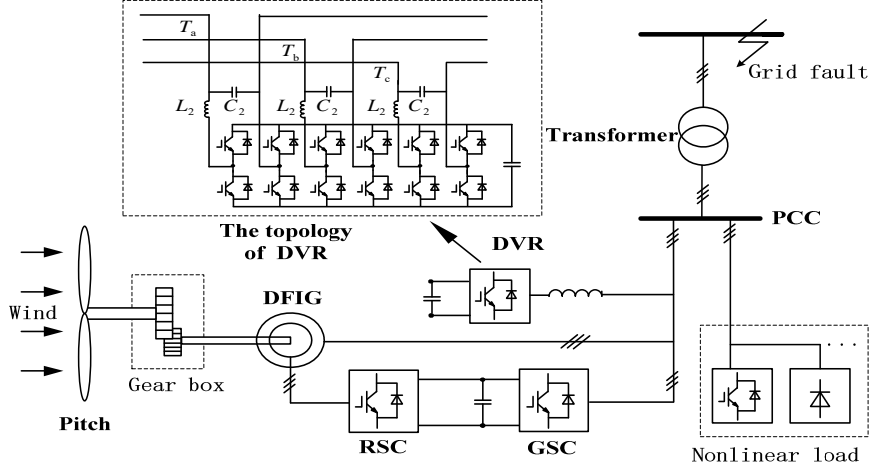

Fig.1 The topology of DFIG system with DVR

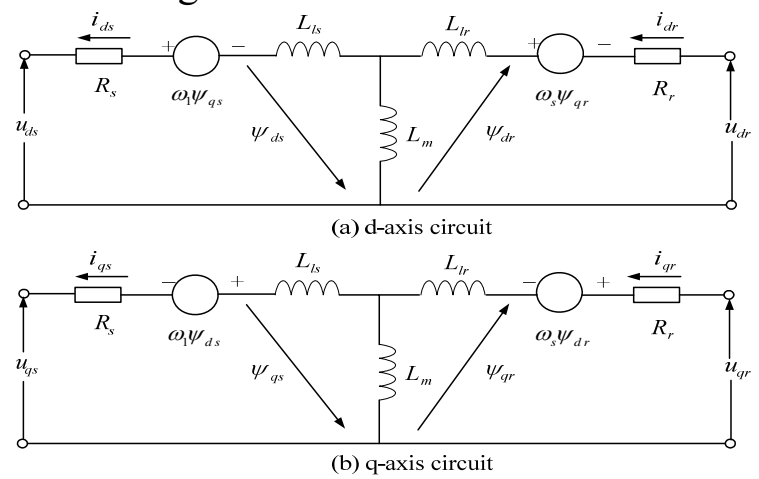

Fig.2 Dynamic d-q equivalent circuits of DFIG

According toFigure2, the voltage equations and flux ones of stator/rotor in $d$ - $q$ coordinate are expressed as:

$$
\begin{gathered}
\left\{\begin{array}{l}
u_{d s}=-R_{s} i_{d s}-p \psi_{d s}+\omega_{1} \psi_{q s} \\
u_{q s}=-R_{s} i_{q s}-p \psi_{q s}-\omega_{1} \psi_{d s}
\end{array}\right. \\
\left\{\begin{array}{l}
u_{d r}=R_{r} i_{d r}+p \psi_{d r}-\omega_{s} \psi_{q r} \\
u_{q r}=R_{r} i_{q r}+p \psi_{q r}+\omega_{s} \psi_{d r}
\end{array}\right. \\
\left\{\begin{array}{l}
\psi_{d s}=L_{l s} i_{d s}+L_{m}\left(i_{d s}-i_{d r}\right)=L_{s} i_{d s}-L_{m} i_{d r} \\
\psi_{q s}=L_{l s} i_{q s}+L_{m}\left(i_{q s}-i_{q r}\right)=L_{s} i_{q s}-L_{m} i_{q r}
\end{array}\right. \\
\left\{\begin{array}{l}
\psi_{d r}=L_{l r} i_{d r}+L_{m}\left(i_{d r}-i_{d s}\right)=L_{r} i_{d r}-L_{m} i_{d s} \\
\psi_{q r}=L_{l r} i_{q r}+L_{m}\left(i_{q r}-i_{q s}\right)=L_{r} i_{q r}-L_{m} i_{q s}
\end{array}\right.
\end{gathered}
$$

Substituting the flux equations into the voltage equations, we obtain the voltage-current equations in the d-q coordinate:

$$
\left[\begin{array}{l}
u_{d s} \\
u_{q s} \\
u_{d r} \\
u_{q r}
\end{array}\right]=\left[\begin{array}{cccc}
-R_{s}-p L_{s} & \omega L_{s} & p L_{m} & -\omega L_{m} \\
-\omega L_{s} & -R_{s}-p L_{s} & \omega L_{m} & p L_{m} \\
-p L_{m} & \omega_{s} L_{m} & R_{r}+p L_{r}-\omega_{s} L_{r} \\
-\omega_{s} L_{m} & -p L_{m} & \omega L_{r} & R_{r}+p L_{r}
\end{array}\right]\left[\begin{array}{c}
i_{d s} \\
i_{q s} \\
i_{d r} \\
i_{q r}
\end{array}\right]
$$

The electromagnetic torque equations can be expressed as:

$$
T_{L}-T_{e}=T_{L}-\frac{3}{2} n_{p} L_{m}\left(i_{d s} i_{q r}-i_{q s} i_{d r}\right)=\frac{1}{n_{p}} J \frac{d \omega_{r}}{d t}
$$

Where $R_{s}$ and $R_{r}$ are the winding resistances of stator and rotor; $L_{s}, L_{r}, L_{m}, L_{l s}, L_{l r}$ are the equivalent self, leakage and mutual inductances between stator and rotor; $u_{d s}, u_{q s}, u_{d r}, u_{q r}$ are the $\mathrm{d}$ - and q-axis components of stator and rotor voltage; $i_{d s}, i_{q s}, i_{d r}, i_{q r}$ are the d- and q-axis components of stator and rotor current; $\psi_{d s}, \psi_{q s}, \psi_{d r}, \psi_{q r}$ are the d- and q-axis components of stator and rotor flux; $\omega_{1}, \omega_{r}, \omega_{s}=\omega_{1}-\omega_{r}$ are the synchronous speed ,rotor speed and slip frequency; 
$p$ is the differential operator; $T_{L}$ is the mechanical torque input by generator; $n_{p}$ is pole-pairs number; $J$ is the rotor moment of inertia.

\section{Impacts of Unbalanced Grid Voltage for DFIG}

Impacts of Unbalanced Grid Voltage for RSC. According to the theory of symmetrical components, any asymmetrical three-phase electromagnetic volume can be broken down into three separate symmetry systems, that is positive, negative, zero sequence components. Zero sequence circuit component can be ignored for neutral isolation of DFIG system.Figure 3 shows the spatial relationships between two-phase static coordinate and forward reverse synchronous coordinate.

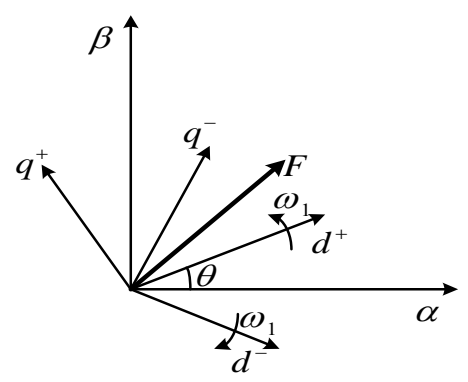

Fig. 3 The two-phase static coordinate and synchronous coordinate

According toFigure 3 , the positive and negative sequence components of electromagnetic vector $F$ are given under the unbalanced grid voltage supply by

$$
F_{\alpha \beta}=F_{\alpha \beta+}+F_{\alpha \beta-}=F_{d q+}^{+} e^{j \omega_{1} t}+F_{d q_{-}}^{-} e^{-j \omega_{1} t}
$$

Where superscripts + and - refer to forward and reversal synchronous rotating frames, respectively. Subscripts + and - denote positive and negative sequence components, respectively.

Under the unbalanced conditions, the active and the reactive power generated by the DFIG stator are calculated as:

$$
P_{s}+j Q_{s}=-\frac{3}{2} U_{s \alpha \beta} \times \hat{I}_{\mathrm{s} \beta \beta}=\left(P_{\mathrm{s} 0}+P_{\mathrm{ssin} 2} \sin 2 \omega t+P_{\mathrm{sos} 2} \cos 2 \omega t\right)+j\left(Q_{\mathrm{s} 0}+Q_{\mathrm{ssin} 2} \sin 2 \omega t+Q_{\mathrm{sos} 2} \cos 2 \omega t\right)
$$

Under the unbalanced conditions, the electromagnetic power is given as:

$$
P_{e}=-\frac{3}{2} \operatorname{Re}\left[j \omega_{1} \psi_{s \alpha \beta} \times \hat{I}_{s \alpha \beta}+j\left(\omega_{1}-\omega_{r}\right) \psi_{r \alpha \beta} \times \hat{I}_{r a \beta}\right]=P_{e 0}+P_{e \sin 2} \sin 2 \omega_{1} t+P_{e \cos 2} \cos 2 \omega_{1} t
$$

Where $P_{e 0}, P_{e \sin 2}$ and $P_{e \cos 2}$ are dc component, double-supply frequency sine and cosine oscillating components of the electromagnetic power.

Similarly, the electromagnetic toque can be expressed as:

$$
T_{e}=\frac{P_{e}}{\Omega_{1}}=\frac{P_{e 0}+P_{e \sin 2} \sin 2 \omega_{1} t+P_{e \cos 2} \cos 2 \omega_{1} t}{\Omega_{1}}
$$

Where $\Omega_{1}=\omega_{r} / n_{p}$ is mechanical rotor angular velocity.

Impacts of An Unbalanced Grid Voltage for GSC. When grid voltage is unbalanced, the GSC output instantaneous active and reactive power can be expressed as:

$$
P_{g}+j Q_{g}=-\frac{3}{2} U_{s \alpha \beta} \times \hat{I}_{g a p}=\left(P_{g 0}+P_{g \sin 2} \sin 2 \omega_{1} t+P_{g \cos 2} \cos 2 \omega_{1} t\right)+j\left(Q_{g 0}+Q_{g \sin 2} \sin 2 \omega_{1} t+Q_{g \cos 2} \cos 2 \omega_{1} t\right)
$$

In addition, regardless of the input impedance, the dc bus voltage equation can be expressed as:

$$
C U_{d c} \frac{d U_{d c}}{d t}=\left(P_{e 0}-P_{s 0}-P_{g 0}\right)+\left(P_{e \sin 2}-P_{s \sin 2}-P_{g \sin 2}\right) \sin 2 \omega_{1} t+\left(P_{e \cos 2}-P_{s \cos 2}-P_{g \cos 2}\right) \cos 2 \omega_{1} t
$$

As can be seen from (11)-(12), similar to the case illustrated, output of the power between the GSC and grid contain active and reactive power oscillating at a double frequency, which further aggravates the ripples in dc-link voltage and deteriorates the qualities of output powers. 


\section{The Positive-And Negative-Sequence Separation of the Resonance Integrator}

The proportional resonance(PR) is able to achieve floating control on a specific frequency $\mathrm{AC}$ signal in static coordinate system. Its transfer function with the function to choose positive sequence angular frequency $\omega$ is designed as:

$$
H(s)=\frac{\omega}{s-j \omega}
$$

Similarly, the transfer function to choose negative sequence angular frequency $-\omega$ is designed as:

$$
H(s)=\frac{\omega}{s+j \omega}
$$

Converting the transfer function(13)and(14)into positive sequence $\operatorname{PR}(\omega)$ and negative sequence $\operatorname{PR}(-\omega)$ circuits with some of the control unit can implement extraction of positive and negative sequence of asymmetric three-phase signal, as shown inFigure4. As the input signal, $u_{\alpha}$ and $u_{\beta}$ are static coordinate system components transformed from three-phase voltage; feedback coefficient $k$ is usually taken 0.707 , which is more appropriate to speed of response and overshoot; $u_{\alpha p}$ and $u_{\beta p}$ are detected fundamental positive sequence components an $u_{\alpha n}$ and $u_{\beta n}$ are negative sequence.

\section{DFIG Wind Turbine System plus DVR of PR Control}

The whole DFIG wind turbine system with three single-phase DVR, as shown in Figure5, mainly consists of DFIG wind turbine system, series DVR and measuring and control parts. The method of positive and negative sequence separation is used to decide whether to close switch or not.

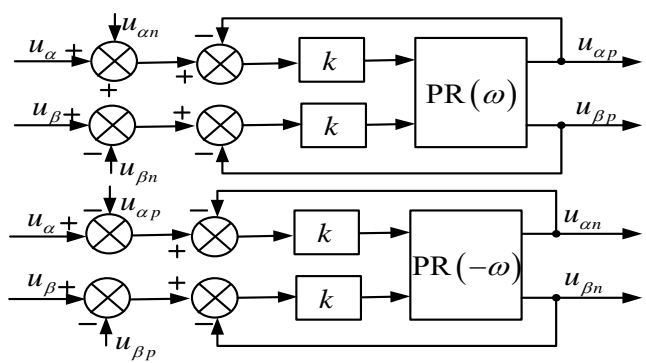

Fig. 4 Positive and negative sequence based on PR

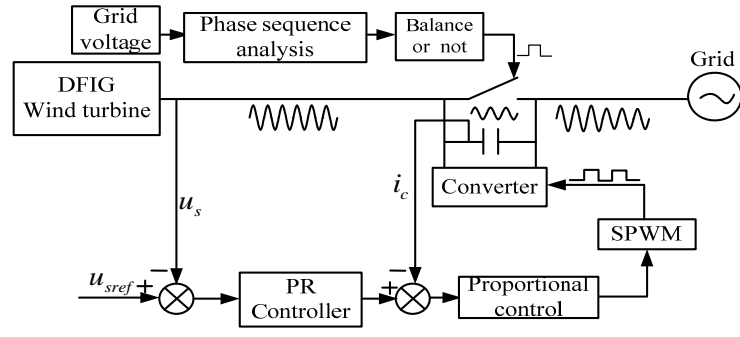

Fig. 5Control block diagram of DVR-DFIG system

Mathematical Model And Control Strategy Of DVR. The DVR is equipped with LC type filter and a voltage source converter, which is directly coupled between generator and grid, so parameters of boosting transformer easily affected can be ignored.Figure6 shows equivalent model of DVR.

InFigure6, $U_{\mathrm{s}}, U_{\mathrm{g}}$ are grid voltage and output voltage of DFIG. $U_{\mathrm{c}}$ is output of compensatory voltage during the voltage dip of grid. $L_{f}, C_{f}$ are inductance and capacitor of LC filter. The sum of equivalent resistance of Inverter switching loss and line resistance of filter inductance loop is $R_{f}$.

The transfer function block diagram of equivalent model of DVR is shown in dashed frame part ofFigure7, called controlled device. No static difference PR controller is expressed as:

$$
G_{P R}(s)=k_{p}+\sum_{n=1,3,5, \ldots} \frac{2 k_{n} \omega_{c} s}{s^{2}+2 \omega_{c} s+\left(n \omega_{0}\right)^{2}}
$$

Bode Diagram of DVR. The relation of output voltage $U_{g}$ and reference voltage $U_{g}^{*}$ extracted fromFigure7 can be expressed as:

$$
G_{1}=\frac{U_{g}}{U_{g}^{*}}=\frac{k_{m} G_{P R} G_{P}}{C_{f} s\left(L_{f} s+R_{f}+k_{m} G_{P}\right)+k_{m} G_{P R} G_{P}+1}
$$


Similarly, output voltage $U_{g}$ and disturbing current $I_{g}$ can be expressed as:

$$
G_{2}=\frac{U_{g}}{I_{g}}=-\frac{L_{f} s+R_{f}}{C_{f} s\left(L_{f} s+R_{f}+k_{m} G_{P}\right)+k_{m} G_{P R} G_{P}+1}
$$

Where $G_{P}$ is inner loop gain, all the parameters needed can be found from Table 2 .

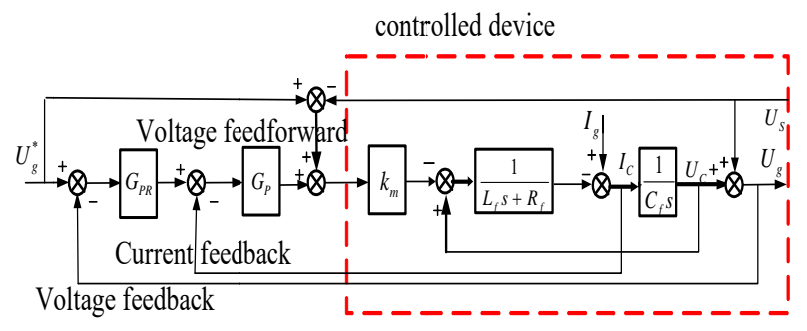

Fig.6 Diagram of DVR equivalent circuit

Fig.7 Structure diagram of DVR complex control strategies

Figure 8 shows the bode diagrams of transfer function $G_{1}$ and $G_{2}$. Bode diagram of $G_{1}$ shows complex control system have a good steady state response to track reference voltage all the time. Bode diagram of $G_{2}$ shows complex control can adapt the change of load, because of small gain within a fairly large frequency range.

Compensation Mechanism of DVR. DVR adopts total compensation strategy, namely, phase and amplitude compensation, as shown inFigure9. When network voltage is unbalanced, leading to negative sequence component, inverter output inverse negative sequence voltage to offset the negative sequence component in the grid.

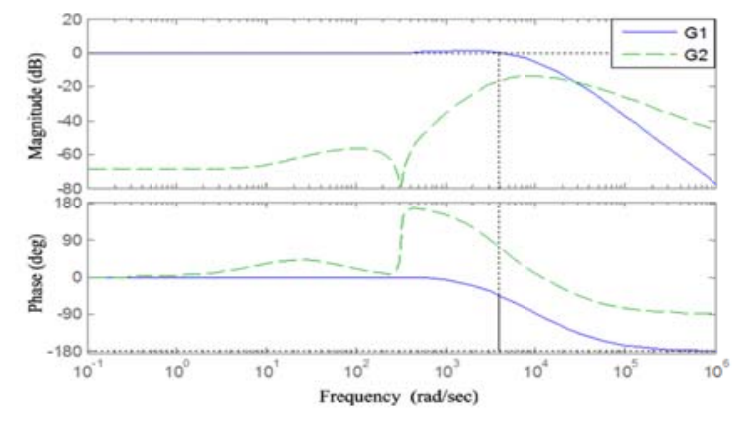

Fig.8 Bode diagrams of transfer function $G_{1}$ and $G_{2}$

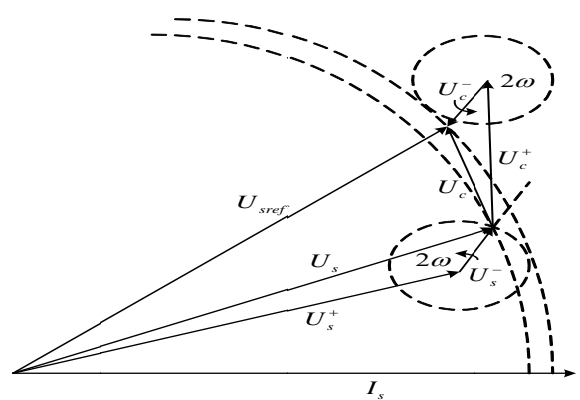

Fig.9 Injected unbalanced voltage diagram of DVR

\section{Simulation Results}

Simulation results are carried out by using MATLAB/Simulink program for a 2MW DFIG wind turbine system and a DVR. The DFIG and DVR parameters are given in Table 1 and 2, respectively. The wind speed is assumed to be $12 \mathrm{~m} / \mathrm{s}$, so the stator active power is controlled at rated power 2 MW.

Table 1 The parameters of DFIG

\begin{tabular}{|c|l|}
\hline Rated power & $2[\mathrm{MW}]$ \\
\hline Stator voltage (phase-phase, $\mathrm{rms})$ & $690[\mathrm{~V}]$ \\
\hline Stator resistance & $0.0108 \mathrm{pu}$ \\
\hline self-inductances of stator & $3.464 \mathrm{pu}$ \\
\hline Rotor resistance & $0.0121 \mathrm{pu}$ \\
\hline self-inductances of rotor & $3.472 \mathrm{pu}$ \\
\hline Inertia constant & $0.5[\mathrm{~s}]$ \\
\hline Grid voltage frequency & $50[\mathrm{~Hz}]$ \\
\hline Pole pairs & 2 \\
\hline DC-link capacity & $16000[\mu \mathrm{F}]$ \\
\hline
\end{tabular}

Table 2The parameters of DVR

\begin{tabular}{|l|l|}
\hline Filter inductance & $0.01[\mathrm{H}]$ \\
\hline Filter capacity & $200[\mathrm{uF}]$ \\
\hline Inner loop gain & 30 \\
\hline Outer loop gain & 1 \\
\hline Resonance factor & 100 \\
\hline Resonance frequency & 314.16 \\
\hline
\end{tabular}


Figure 10 shows the conventional PI controller simulation results of DFIG with a $6 \%$ three phases grid voltage balanced sag occurs at $1.5 \mathrm{~s}$, while a $10 \%$ unbalanced grid voltage fault of a phase occurs at $1.8 \mathrm{~s}$, and the grid voltage is recover to normal value from unbalance at $2.1 \mathrm{~s}$. The RSC and GSC of DFIG is controlled with conventional PI controller to realize the power decoupling control. As shown in Figure 10(b), the GSC produce negative-sequence voltage component, which leads to the stator active and reactive powers, stator and rotor currents and electromagnetic torque oscillating atsignificant $100 \mathrm{~Hz}$ oscillations in Figure $10(\mathrm{c}-\mathrm{e})$ and (g-h). At the same time, the DC voltage also produce ripples at double grid frequency in Figure 10(f). The PI control method can't provide accurate regulation of the negative sequence component of DFIGDVR.

Figure 11shows operation performance of DFIG with DVR plus PR controller during grid voltage fault. The grid fault type is same with Figure 10. Whether the grid voltage balance/unbalance sags occur seriously or not, the grid-side converter voltage stay constant in Figure 11(a). The PR controller regulate negative-sequence voltage component recover to zero in case of grid voltage fault. Consequently, the stator output active power oscillation is compensated by the GSC. This leads to the electromagnetic torque and DC voltage are eliminated effectively and rapidly. The DVR injects the compensation voltage for DFIG shown in Figure 11(i), by which the DFIG operates safely and stably. The DVR can compensated all kind of voltage drop in theory, which greatly improves the universal fault ride-through operation ability of DFIG wind turbine.
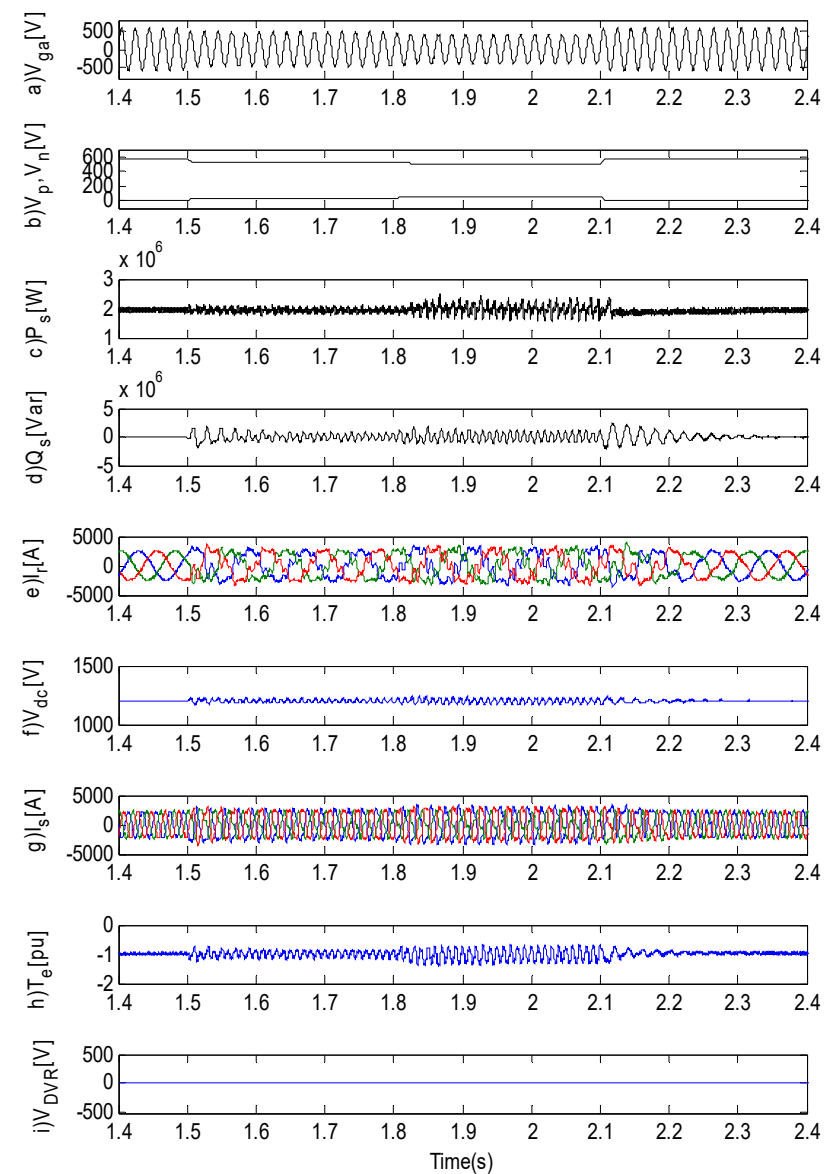

Fig.10 Simulation of DFIG performance without DVR protection during different grid unbalance. (a)Grid voltage of a phase. (b)Positive-sequence and negativesequence voltage. (c)Active stator power. (d)Reactive stator power. (e)Rotor current. (f)Converter dc voltage. (g)stator current. (h)DFIG electromagnetic torque. (i)DVR output voltage.
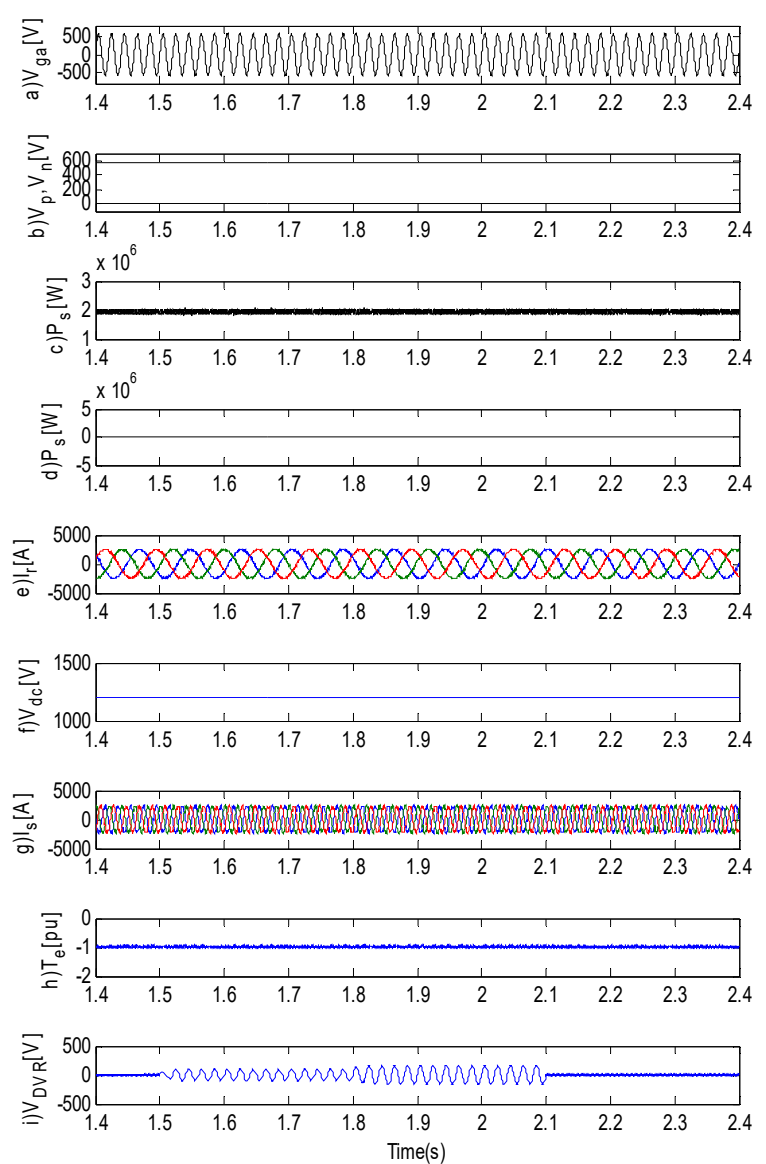

Fig.11 Simulation of DFIG performance with DVR protection during different grid unbalance. (a)Grid voltage of a phase. (b)Positive-sequence and negativesequence voltage. (c)Active stator power. (d) Reactive stator power. (e)Rotor current. (f)Converter dc voltage. (g)stator current. (h)DFIG electromagnetic torque. (i) DVR output voltage. 


\section{Acknowledgements}

This work has been financially supported by the National Natural Science Foundation of China (51567020, 51367012), Natural Science Foundation of Inner Mongolia (2015MS0532, 2011BS0903).

\section{References}

[1] Ibrahlm, A. O.; Nguyen, T. H.; Lee, D. C. A fault ride-through technique of DFIG wind turbine systems using dynamic voltage restorers, IEEE Transactions on Energy Conversion, 26, 3(2011), pp. 871-882.

[2] Wessels, C.; Gebhardt, F.;Fuchs, F. W. Fault ride-through of a DFIG wind turbine using a dynamic voltage restorer during symmetrical and asymmetrical grid faults, IEEE Transactions on Power Electronics, 26, 3(2011), pp. 807-815.

[3] Asha Rani, M. A.; Nagamani, C. An effective reference generation scheme for DFIG with unbalanced grid voltage, IEEE Transactions on Sustainable Energy, 5, 3(2014), pp. 1010-1017.

[4] Asha Rani, M. A.; Karthikeyan, A.; Nagamani, C. Decoupled control of doubly-fed-induction generator under unbalanced grid voltage with modified reference generation, International Conference on Power, Energy and Control, Dindigal, 2013, pp. 420-425.

[5] Hu, J. B.; He, Y. K.; Xu, L. Improved control of DFIG systems during network unbalance using PI-R current regulators., IEEE Transactions on Industial Electronics, 56, 2(2009), pp. 439-451.

[6] Liu, C. j.; Xu, D. H.; Zhu, N.; Blaabjerg, F.; Chen, M. DC-voltage fluctuation elimination Through a DC-capacitor current control for DFIG converters under unbalanced grid voltage conditions, IEEE Transactions on Power Electronics, 28, 7(2013), pp. 3206-3218.

[7] Hu, J. B.; Xu, H. L.; He, Y. K. Coordinated control of DFIG's RSC and GSC under generalized unbalanced and distorted grid voltage conditions, IEEE Transactions on Industial Electronics, 60, 7(2013), pp. 2808-2819.

[8] Hu, J. B.; He, Y. K.; Xu, L.; Zhi, D.W. Predictive current control of grid-connected voltage source converters during network unbalance, IET on Power Electronics, 3, 5(2010), pp. 690-701.

[9] Nian, H.; Song, Y.; Zhou, P.; He, Y. Improved direct power control of a wind turbine driven doubly fed induction generator during transient grid voltage unbalance, IEEE Transactions on Energy Conversion, 26, 3(2011), pp. 976-985.

[10] Hu, J. B.; He, Y. K. Reinforced control and operation of DFIG-based wind power generation system under unbalanced grid voltage conditions, IEEE Transactions on Energy Conversion, 24, 4(2009), pp. 905-915.

[11] Martinez, M. I.; Tapia, G.; Susperregui, A.; Camblong, H. DFIG Power Generation Capability and Feasibility Regions Under Unbalanced Grid Voltage Conditions, IEEE Transactions on Energy Conversion, 26, 4(2011), pp. 1051-1062.

[12] Hu, J. B.; He, Y. K. Reinforced control and operation of DFIG-based wind power generation system under unbalanced grid voltage conditions, IEEE Transactions on Energy Conversion, 24, 4(2011), pp.905-915.

[13] Leon, A. E.; Mauricio,J. M.; Solsona, J. A.Fault ride-through enhancement of DFIG-based wind generation considering unbalanced and distorted conditions, IEEE Transactions on Energy Conversion, 27, 3(2012), pp. 775-783. 